\title{
INFLUÊNCIA DO ENOS NA DISTRIBUIÇÃO DAS PRECIPITAÇÕES NO ESTADO DO PARANÁ, BRASIL.
}

\author{
TEIXEIRA, Nivaldo Fernandes - nfernate10@alumnes.ub.edu \\ MARTÍN-VIDE, Javier - jmartinvide@ub.edu
}

Dep Geog Física e Análise Geográfica Regional - Universidade de Barcelona/Espanha

\begin{abstract}
RESUMO
O objetivo deste artigo é correlacionar a precipitação do estado do Paraná, com o índice El Niño-Oscilação Sul 3.4 (iENOS). Para tanto foram selecionadas séries pluviométricas, no período de 1976 a 2011, de 22 postos pluviométricos pertencentes ao Instituto Agronômico do Paraná (IAPAR), ao Sistema Meteorológico do Paraná (SIMEPAR) e ao Instituto Nacional de Meteorologia (INMET). A metodologia de análise utilizada consistiu em relacionar os iENOS do trimestre dezembro, janeiro e fevereiro (DJF) de cada ano da série pluviométrica analisada, com os totais mensais acumulados das precipitações pluvias, para o mesmo trimestre. Também foi analisado o índice (iENOS) com as chuvas trimestrais defasada, procurando encontrar a melhor associação entre o índice e a precipitação trimestral. Essa relação foi estabelecida através do método estatístico denominado de correlação de Pearson ( $r$ ). Finalmente foi elaborado mapa utilizando o programa SURFER 8, que corroboraram os resultados e discusões apresentados.
\end{abstract}

Palavras-chaves: Análise de correlação, iENOS, Paraná, precipitação. INFLUENCE OF ENSO DISTRIBUTION OF PRECIPITATION IN PARANÁ STATE, BRAZIL.

\section{ABSTRACT}

The aim of this paper is to correlate the precipitation State of Paraná, with the index El Niño - Southern Oscillation 3.4 (ENOSi). The study selected rainfall series for the period 1976-2011 of 22 rain gauges belonging to the Agronomic Institute of Paraná (IAPAR), the Meteorological System of Paraná (SIMEPAR), and the National Institute of Meteorology (INMET). The analysis methodology used consisted in relating ENOSi quarter of December, January and February (DJF) of rainfall each year of the series analyzed, with monthly totals of accumulated rainfall, for the same quarter. It was also analyzed index (ENOSi) with rain quarterly lagged, trying to find the best association between the index and quarterly precipitation. This relationship was established by statistical method called correlation coefficient ( $r$ ). Finally map was prepared using the program SURFER 8, which corroborated the results and discussion presented.

Key words: Correlation analysis, ENSOi, Paraná, precipitation.

\section{INTRODUÇÃO}

A variabilidade interanual denominada El Niño-Oscilação Sul (ENOS) é um dos padrões de teleconecções mais importante em escala global. Estes eventos ocorrem em decorrência do aumento da temperatura da superfície do mar no oceano Pacífico Equatorial, assim como o debilitamento dos ventos alísios, 
provocando variabilidade pluviométrica em grande parte da superfície terrestre. Por exemplo, no sul do Brasil, com a ocorrência dos eventos ENOS (fase quente) ocorre chuvas acima da média, nesta região. Por outro lado, na região Nordeste as anomalias pluviométricas são negativas, ou seja, chove abaixo da média (KUCHARSKI et al., 2008). Entretanto, nem todos El Niño produzem secas no nordeste ou chuvas no sul do Brasil. Essa associação fica mais clara entre os El Niños mais intensos e as grandes secas na região Nordeste ou as marcadas inundações no sul do Brasil. Kane (2001) estima que $40 \%$ dos eventos El Niño não produzem seca na citada região. No estudo das chuvas da região Nordeste é importante observar também, a temperatura superficial das águas do Atlântico, assim como a posição da Zona de Convergência Intertropical (ZCIT) (NOBRE e SHUKLA, 1996). Já para o sul do Brasil, Cataldi e e Torres (2006) explicam que as anomalias das temperaturas das águas atlânticas são decisivas na explicação das chuvas dessa região.

Em relação ao sul do Brasil, a influência do El Niño é conhecida (GRIMM et al., 2000), assim como nos países vizinhos (SCIAN, 2000). Em geral, durante um episódio de El Niño e no trimestre de dezembo até fevereiro as chuvas são quantitativamente mais significativas do que a habitual no sul do Brasil (www.cpc.ncep.noaa.gov/products/analysis_monitoring/ensocycle/elninosfc.sht $\mathrm{ml}$ ). Para Lucero (1993), as chuvas da bacia hidrográfica do rio Paraná, especialmente do rio Iguaçu tem marcada influência do El Niño.

Neste trabalho são analizados os padrões espaciais da correlação entre o El Niño e a precipitação e a defasagem intrínseca da precipitação no Paraná.

\section{- Área de estudo: estado do Paraná}

O Paraná está localizado entre as coordenadas geográficas de $22^{\circ}$ e $26^{\circ}$ de latitude sul, e $48^{\circ}$ e $54^{\circ}$ de longitude oeste (Figura 1). É um dos 26 estados federativos do Brasil, localizado na parte setentrional da região Sul. Sua área territorial é de 199.316,7 km², contabilizando mais de 10,4 milhões de habitantes (IBGE, 2010) distribuídos irregularmente em 399 municípios.

O estado ostenta grandes diversidades de relevo (Figura 1), solo e clima (Figura 2), que proporcionam ambientes favoráveis para o desenvolvimento de espécies vegetais nativas e também o cultivo de grande número de espécies agroindustriais. As altitudes do território variam de 0 a $1.300 \mathrm{~m}$, se compondo de forma fragmentada em Planície Litorânea, Serra do Mar, Primeiro Planalto ou Planalto de Curitiba, Segundo Planalto ou Planalto de Ponta Grossa e Terceiro Planalto ou Planalto de Guarapuava. No livro intitulado Domínios Morfoclimáticos Brasileiros de Ab'Sáber (2003), o autor propõe o uso de seis nomenclaturas distintas para todo o Brasil, das quais três estão caracterizadas no estado do Paraná. Segundo o mesmo, a proposta é de manter estritas correlações com o clima, vegetação, solo, dentre outros. 


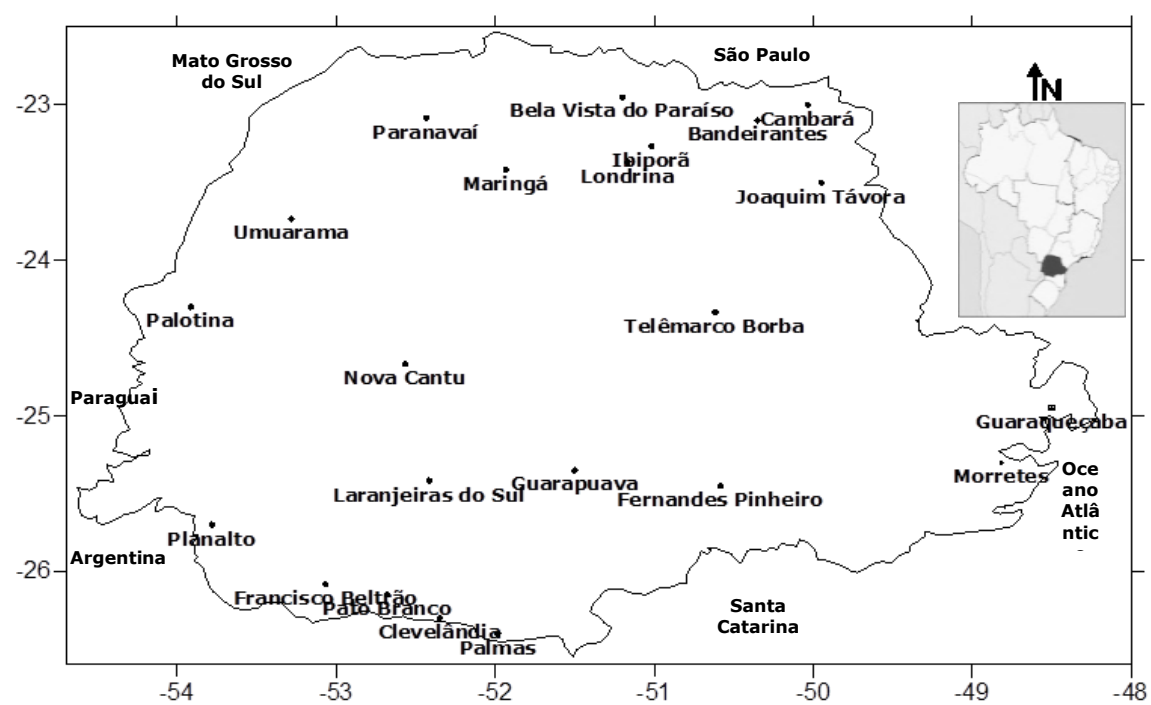

Figura 1. Mapa de localização dos postos pluviométricos no Paraná.

Ainda de acordo com Ab'Sáber (2003), o primeiro domínio está localizado na faixa litorânea e apresenta Mares de Morros com acentuado intemperismo químico, significativa rede de drenagem, chuvas distribuídas ao longo do ano, entre 1.100 a $1.800 \mathrm{~mm}$ ou mais, fortes influências das massas de ar atlânticas e presença de latossolos e podzólicos. O segundo domínio, Araucárias, situado no planalto meridional do PR, com altitudes que oscilam entre 500 a $1.200 \mathrm{~m}$ apresentam árvores com mais de 30 metros de altura e precipitações de 1.200 a $1.800 \mathrm{~mm}$ anuais. Os solos se caracterizam como latossolos brunos e roxos, cambissolos, terras brunas e solos litólicos, fortes ondulações e montanhas. Finalmente a faixa de transição, localizada a oeste do estado, apresenta mares de morros e planaltos, vegetações diversificadas de araucárias, campos, cerrados, e florestas.

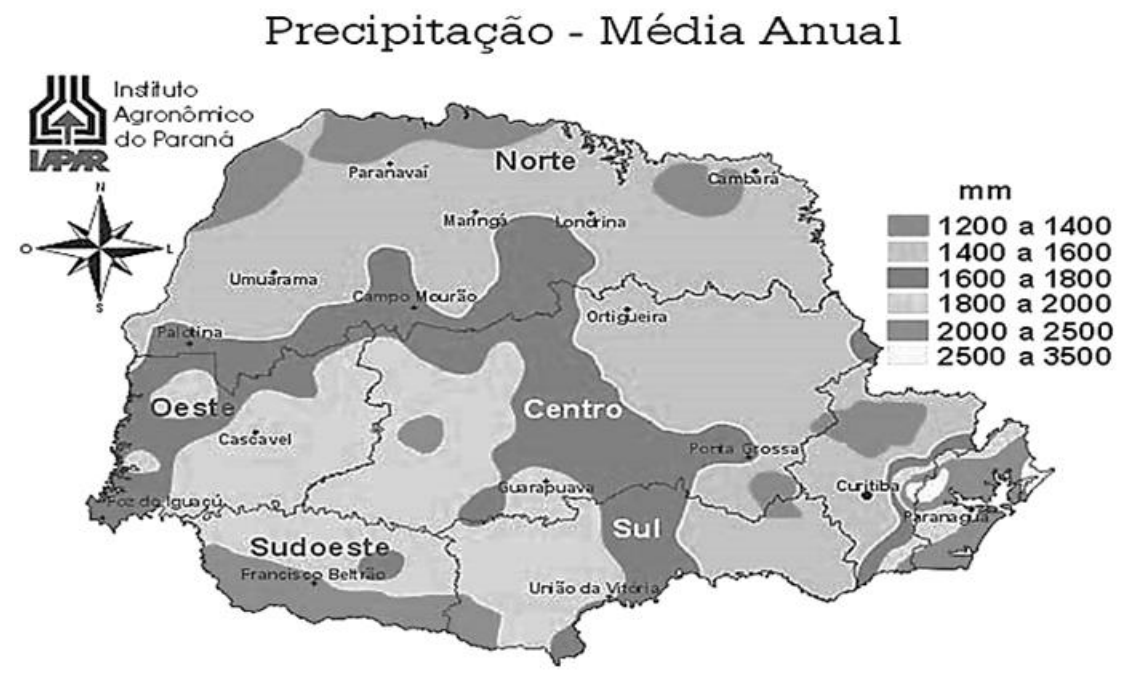

Figura 2. Mapa da precipitação média anual, Paraná.

Fonte: IAPAR, 2012. 
A classificação climática de Köppen pode perfeitamente ser aplicada no estado do Paraná. Segundo Trewartha \& Horn (1980), esta distribuição baseia-se nos parametros da vegetação, temperatura e pluviosidade de determinada região e está definida por um código de letras, que representam grandes grupos e subgrupos climáticos e que também possui subdivisões para identificar características estacionais de temperatura e pluviosidade.

O IAPAR (2012) define que é importante o conhecimento do tipo climático de uma região, pois fornecem indicativos de larga escala sobre as condições médias de pluviosidade e temperatura esperados.

Segundo a classificação de Köppen, o clima subtropical (Cfa) possui temperatura média no mês mais frio inferior a $18^{\circ} \mathrm{C}$, ou seja, mesotérmico e temperatura média do mês mais quente acima de $22^{\circ} \mathrm{C}$. Deste modo os verões são quentes, quase não ocorrem geadas, subsistindo disposição para a concentração de chuvas na estação de verão e reduzida probabilidade de estação seca definida. O clima temperado $(\mathrm{Cfb})$ é igualmente mesotérmico, pois apresenta temperatura média no mês mais frio abaixo de $18^{\circ} \mathrm{C}$, os verões são frescos, a temperatura média do mês mais quente está abaixo de $22^{\circ} \mathrm{C}$ e também não possui estação seca definida.

De acordo com o IAPAR (2012), o clima temperado-continental do estado apresenta grandes amplitudes anuais, pois não sofre o efeito regulador do oceano. No verão as temperaturas podem chegar a $22^{\circ} \mathrm{C}$ e no inverno a $0^{\circ} \mathrm{C}$, dependendo da região do estado. Entretanto, as precipitações seguem perfeitamente distribuídas ao longo do ano (Figura 2). Segundo estudos deste mesmo Instituto, se baseando na frequência média anual dos ventos, o Paraná possuem três componentes: nordeste, leste, e sudeste.

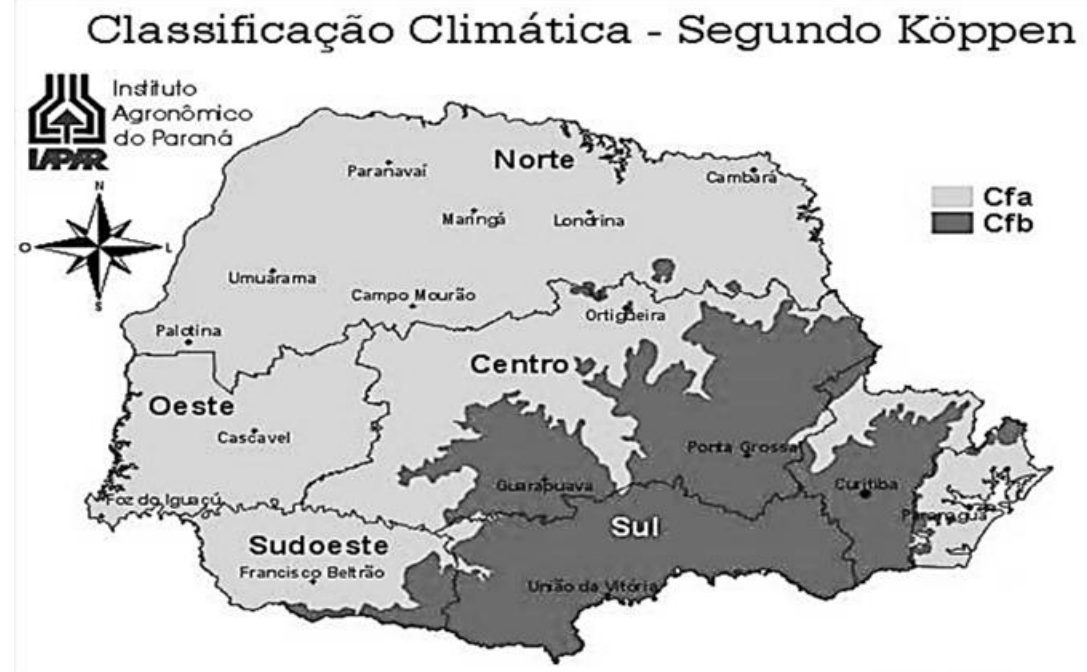

Figura 3. Mapa de classificação climática, Paraná.

Fonte: IAPAR, 2012.

Basicamente dois tipos de vegetações compõem a cobertura em todo o estado, a floresta Atlântica, que compreende do litoral à Serra do Mar e as Matas das Araucárias ou Pinheiro Brasileiro, que recobrem as regiões de planalto e de 
clima subtropical. O estado desfruta de duas grandes bacias hidrografias, a do rio Paranapanema e a do rio Paraná. Esta última, a mais importante, pois é a detentora de efectiva produção energética nacional e internacional.

A agropecuária e o extrativismo são atividades econômicas que correspondem a percentual significativo do PIB do estado. Neste sentido, os estudos climáticos são fundamentais para a gestão administrativa, pois auxilia no planejamento e na elaboração de projetos e na efetividade de implementação de políticas públicas e privadas. Sabe-se desde tempos remotos que o conhecimento climatológico de determinada região proporciona o uso eficaz e eficiente dos recursos ambientais nela existente ou inseridos. Mendonça (2001) corrobora quando enfatiza que a ocorrência de chuva é considerada evento essencial a toda a atividade do setor primário da economia paranaense, mas, nem toda forma de chuva é apreciada pelo setor. Cabe analisar em que estação e circunstância atmosférica vão ocorrer tais chuvas, pois podem passar de solução a problema. As precipitações sólidas (granizos) ou líquidas em elevadas quantidades em curto espaço de tempo, não são apreciadas, sobretudo por agricultores.

O trabalho do IAPAR denominado Cartas Climáticas revela ser a chuva a componente climática que mais interfere na produtividade agrícola do estado. Desta forma, esse Instituto difunde o peso significativo dos padrões da precipitação (quantidade anual e distribuição), que tem carácter essencial, além de indicarem os tipos mais adequados de vegetação (espécie e variedade), tipos de atividades (manual ou mecanizada) para cada região, época de plantio e colheita. Além de realizarem a divulgação do calendário agrícola que tem função orientativa aos 230.751 estabelecimentos agropecuários existentes no território. Com base na importância dessas chuvas é que se propõe, neste trabalho, a análise da chuva, através da correlação linear (método de Pearson), associada aos ENOS, para entender parte da frequência, persistência durante os últimos 20-30 anos.

\section{MATERIAL E MÉTODOS}

Para o desenvolvimento desse trabalho foram utilizadas 21 estações meteorológicas da base de dados do IAPAR, SIMEPAR e INMET (Tabela 1). Inicialmente os valores totais das precipitações mensais, correspondentes ao período histórico analisado (1976-2011), foram organizados em planilhas no ambiente Excel. Posteriormente se realizou os acoplamentos dos valores de precipitações em períodos de três meses - exemplo: DJF, JFM e FMA, caracterizados como defasagem 0,1 , 2, etc., para, na sequência certificar-se qual a mais significativa de cada estação investigada.

Para analisar a existência de correlação do iENOS com a precipitação em cada estação, se utilizou a função do coeficiente de correlação de Pearson ou simplesmente "r de Pearson". A aplicação desta função estatística permite calcular o grau da correlação, que possui variabilidade entre -1 (correlação negativa perfeita) e +1 (correlação positiva perfeita). Trata-se de uma análise correlacional, que indica a correspondência linear de duas variáveis quantitativas, neste caso específco do iENOS (DJF) e os valores totais das 
precipitações acumuladas no mesmo trimestre, para cada ano da série estudada, bem como para os trimestres seguintes de cada estação.

Com os resultados dos valores de "r de Pearson" de cada estação foi possível organizar uma tabela, para posteriormente serem confeccionados os gráficos, para o trimestre mais significativo de cada estação. Este processamento em ambiente Excel possibilitou, na sequência, as confecções dos mapas que contribuiram para as análises e discusões dos resultados obtidos, bem como a espacialização das 22 estações do Paraná analisadas. No processo de construção dos mapas se utilizou o "software SURFER", versão 8.

\begin{tabular}{|c|c|c|c|c|c|}
\hline No & Estações & $\begin{array}{lll}\mathbf{X} & \mathbf{Y} \\
\end{array}$ & Correlação(DJF) & Defasagem & Altitude $(\mathrm{m})$ \\
\hline 01 & Bandeirantes & $-50,21-23,06$ & 0,36 & 4 & 440 \\
\hline 02 & Bela Vista do Paraíso & $-51,12-22,57$ & 0,44 & 3 & 600 \\
\hline 03 & Cambará & $-50,02-23,00$ & 0,36 & 4 & 450 \\
\hline 04 & Clevelândia & $-52,21-26,25$ & 0,53 & 3 & 930 \\
\hline 05 & Fernandes Pinheiro & $-50,35-25,27$ & 0,56 & 3 & 893 \\
\hline 06 & Francisco Beltrão & $-53,04-26,05$ & 0,57 & 3 & 650 \\
\hline 07 & Guarapuava & $-51,30-25,21$ & 0,52 & 3 & 1.058 \\
\hline 08 & Guaraqueçaba & $-48,32-25,16$ & 0,05 & 5 & 40 \\
\hline 09 & Ibiporã & $-51,01-23,16$ & 0,43 & 3 & 484 \\
\hline 10 & Joaquim Távora & $-49,57-23,30$ & 0,48 & 3 & 512 \\
\hline 11 & Laranjeiras do Sul & $-52,25-25,25$ & 0,57 & 3 & 880 \\
\hline 12 & Londrina & $-51,10-23,22$ & 0,53 & 3 & 585 \\
\hline 13 & Maringá* & $-50,02-23,00$ & 0,42 & 3 & 450 \\
\hline 14 & Morretes & $-48,49-25,30$ & 0,29 & 4 & 59 \\
\hline 15 & Nova Cantu & $-52,34-24,40$ & 0,53 & 3 & 540 \\
\hline 16 & Palmas & $-51,59-26,29$ & 0,58 & 3 & 1.100 \\
\hline 17 & Palotina & $-53,55-24,18$ & 0,45 & 3 & 310 \\
\hline 18 & Paranavaí & $-52,26-23,05$ & 0,44 & 3 & 480 \\
\hline 19 & Pato Branco & $-52,41-26,07$ & 0,62 & 3 & 700 \\
\hline 20 & Planalto & $-53,47-25,42$ & 0,65 & 3 & 400 \\
\hline 21 & Telêmarco Borba & $-50,37-24,20$ & 0,58 & 3 & 768 \\
\hline 22 & Umuarama & $-53,17-23,44$ & 0,47 & 3 & 480 \\
\hline
\end{tabular}

Tabela 1. Estações Meteorológicas Analisadas no Paraná

\section{RESULTADOS E DISCUSSÃO}

O mapa das isolinhas da Figura 4 descreve para a área territorial paranaense, o grau de correlação através da $r$ de Pearson entre as precipitações, aqui representada pelo somatório dos valores registrados no trimestre de DJF, de cada mês e ano do período investigado e os valores do iENOS correspondente aos mesmos meses (DJF) e anos. Estas correlações foram consideradas nulas ou não significativas para valores de "r de Pearson" menores que 0,33 e para valores acima deste patamar foram consideradas significativas. Os níveis de confiança foram respectivamente de $95 \%$ e $99 \%$. Entretanto os valores superiores a 0,43 apresentaram níveis de confiança $>99 \%$.

A área onde a correlação é significastivamente baixa ou não significativa, corresponde à linha de costa - leste, onde ENOS não tem influência devido a questões longitudinais, geomorfológicas - Serra do Mar e parte do Primeiro 
Planalto ou Planalto de Curitiba - e principalmente devido a grande influência do Atlântico. Nesta zona é marcante o domínio de massas de ar tropical marítimo, que se formam no oceano Atlântico Sul durante a estação de verão, produzindo fluxos que são direcionados ao continente com auxílio do Anticiclone Subtropical do Atlântico Sul (ASAS). Também ocorrem interferência de massas de ar polar marítimo que alcançam a planície litorânea do Paraná, aportando muita umidade e frio, ou seja, chuvas abundantes e baixas temperaturas, o que poderia impedir o avanço das chuvas oriundas do Pacífico (oeste).

Em grande parte do território paranaense, representado por uma longa faixa continua, que se estende do sul-sudeste, passando pelo norte, interpondo o oeste e finalmente o sudoeste do estado, a correlação é marcada. Ela tem ligação com a geomorfologia, associada às altas altitudes do sul, e também as regiões mais baixas do Paraná, demonstrando que o fator relevo em seus extremos, possui estreitas relações com as retenções de massas de ar procedentes do Pacífico sul, portanto relacionadas diretamente com a ENOS.

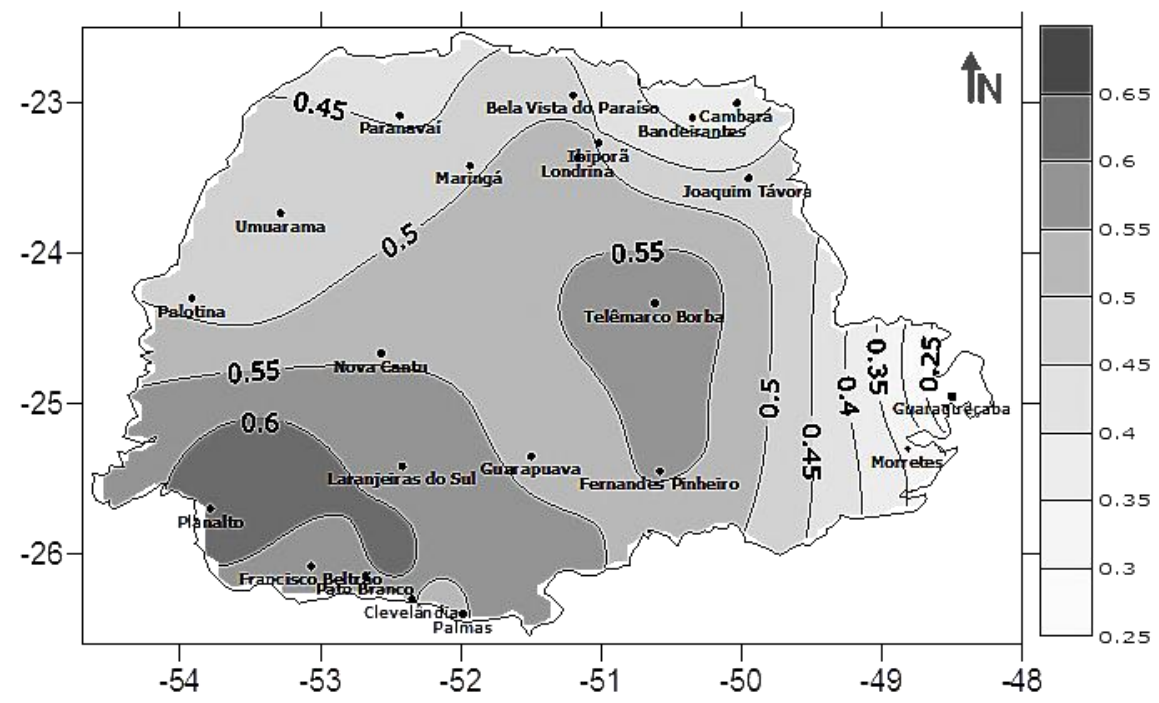

Figura 4. Mapa de correlação do iENOS (DJF) versos precipitação total - defasagem 3 (MAM), Paraná.

Os valores mais altos se encontram no centro e parte do Sudoeste do estado, apresentando valores de correlações das precipitações com a iENOS bastante marcadas. Este grupo possui robustas relações com o Terceiro Planalto ou Planalto de Guarapuava, confirmando que o fator altitude exerce importante influência nas retenções de massas de ar que, logo após transporem a barreira da cordilheira dos Andes, voltaram a circular na baixa atmosfera contribuindo e influenciando nas precipitações do Paraná.

No caso em estudo a distribuição no mapa das isolinhas proporciona vista harmônica, com gradiente orientado no sentido sudoeste a nordeste, também abrangendo o sul e o centro do estado. Estas regiões apresentaram altos e moderados valores na relação entre iENOS e as precipitações. Contudo, cabe lembrar que os valores representativos das correlações limitam-se ao Primeiro Planalto ou Planalto de Curitiba, pois o fator relevo, por meio da Serra do Mar dificulta que as precipitações oriundas do oeste avancem ao leste do estado. No 
sentido leste - oeste, em plena Faixa Litorânea prevalecem os regimes de chuvas característicos de massas - Tropical Atlântica (mTa) e Polar Atlântica $(\mathrm{mPa})$, que, em sua trajetória ao continente, igualmente encontram a Serra do Mar, atuando como barreira (barlavento) para estas componentes, limitando a influência destas à Planície Costeira do estado.

Observando a Figura 5 nota-se o domínio no território paranaense da defasagem 3 (MAM), com uma pequena faixa no nordeste e na costa litorânea correspondente as defasagens $4(\mathrm{AMJ})$ e 5 (MJJ). Desta forma, a defasagem 3 se ajusta a melhor correlação significativa e positiva, entre o iENOS (DJF) e as precipitações que ocorrem no trimestre de março, abril e maio (MAM). Em percentual equivale a $81,8 \%$ ou significativa em 18 das 22 estações do IAPAR analisadas. A defasagem 4, no trimestre abril, maio e junho (AMJ), representa a $13,6 \%$ ou 3 estações, sendo Bandeirantes e Cambará (Nordeste) e Morretes (leste). Por último, a defasagem 5, no trimestre maio, junho e julho (MJJ), equivale a 4,6\%, ou a estação de Guaraqueçaba, entre as 22 aqui analisadas.

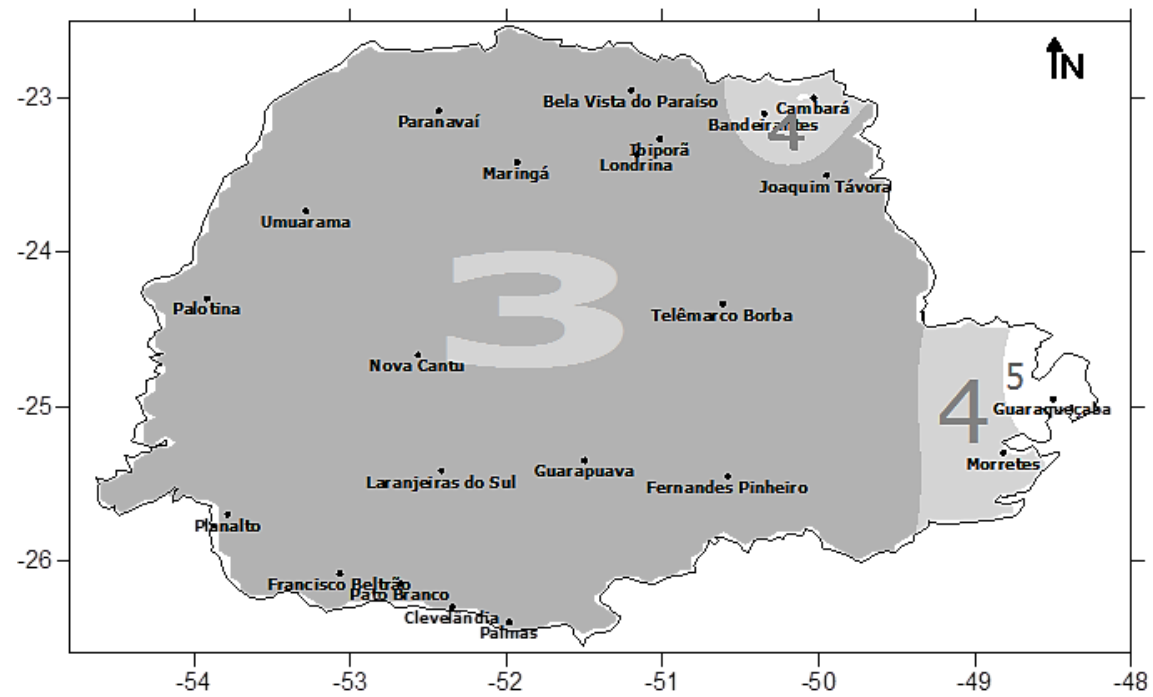

Figura 5. Mapa do iENOS (DJF) e as defasagens de precipitações totais dos trimestres $(M A M=3),(A M J=4)(M J J=5)$, Paraná.

Resumindo, no Paraná o máximo pluviométrico fortemente infuenciado pelo ENOS ocorre com maior correlação no trimestre de março, abril e maio, Figura 6, ou seja, para o iENOS de trimestre dezembro, janeiro e fevereiro tem-se que a chuva no estado refere-se a defasagem 3, exceto a leste do estado, nas defasagens $4(\mathrm{AMJ})$ e $5(\mathrm{MJJ})$. Como exemplo caraterístico, na Figura 6 estão representados os valores da "r de Pearson", para as diferentes defasagens na estação de Londrina. O valor mais alto corresponde a defasagem 3, com valor de $r=0,53$. Nota-se que o valor da "r de Pearson" para a defagem 4, também é significativa. Além disso, na defasagem 9 o valor, ainda que não significativo, sobe, o que poderia indicar uma ciclicidade semi-anual, características comuns a outras estações e que também foram constatadas neste estudo. 


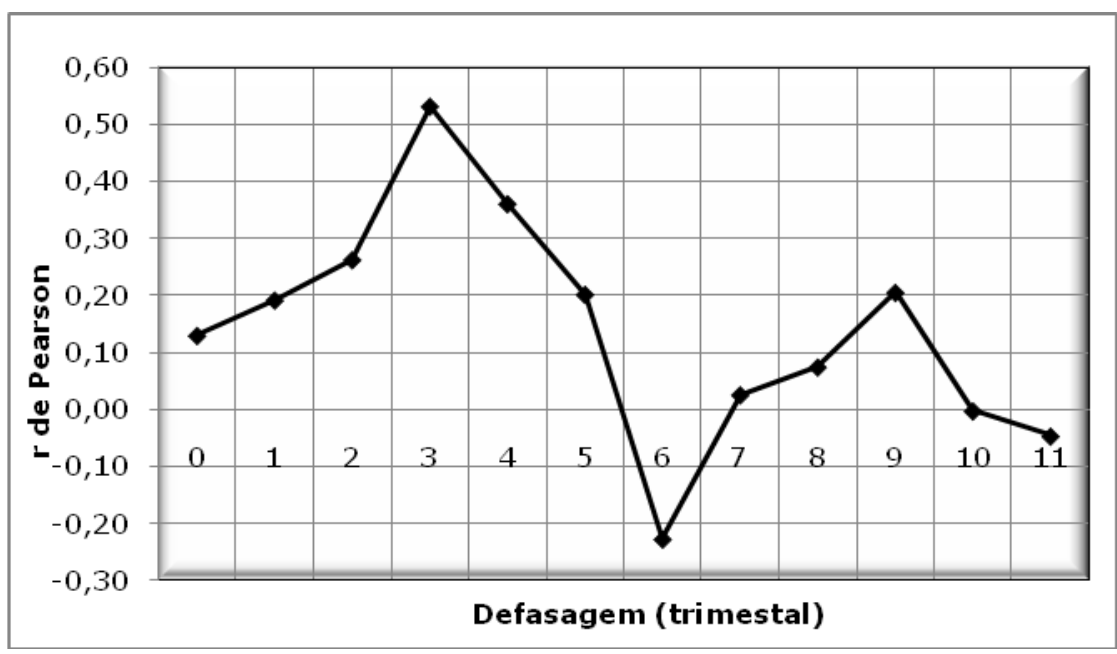

Figura 6. Correlação iENOS (DJF) versos as precipitações dos trimestres DJF (defasagem 0), JFM (defasagem 1), FMA (defasagem 2), MAM (defasagem 3) e seguintes em Londrina, PR.

\section{CONCLUSÃO}

Ainda nos dias atuais, os resultados dos estudos climáticos seguem carregados de incertezas e obviamente longe das respostas finais para o tema dos graus de influências das grandes circulações atmosféricas sobre as precipitações. Logo, cabe aos investigadores desta matéria seguirem buscando explicações para tais incertezas de eventos anteriormente sucedidos, como para eventos climáticos/atmosféricos futuros, por meio da construção de uma base de estudos científicos sólida e confiável. Neste sentido espera-se que este trabalho possa contibuir e auxiliar na compreensão de alguns eventos climáticos ocorridos no PR, sobretudo no período estudado.

As análises dos dados das precipitações médias registradas demonstram, os moderados e altos graus de correlações entre as precipitações e o iENOS (DJF), para o período analisado de 1976-2011, que se refere a uma série histórica suficientemente larga. A defasagem 3, ou seja, as precipitações totais dos meses de março, abril e maio atingem praticamente todo o estado do Paraná. Os resultados das altas correlações ajustam-se às estações situadas em cotas mais elevadas do relevo. Afirmação baseada na aplicação da correlação linear, que resultou valores significativos para a defasagem 3. Portanto, a ocorrência do El Niño, expressada aqui pelo iENOS (DJF) produz chuvas mais altas que a normal três meses depois no estado, ou seja no trimestre de março, abril e maio. Logo, se pode afirmar que as alterações das temperaturas na superfície do oceano Pacífico, que produzem grandes massas de ar úmidas e que ultrapassam a cordilheira dos Andes, associada a dinâmica atmosférica estão relacionadas positivamente com as precipitações no estado do Paraná. 
Nota.

Este texto é uma homenagem à Profa. Dra Leonor Marcon da Silveira que, durante sua estada em Barcelona para desenvolver parte do projeto do qual esta publicação faz parte, veio a falecer.

\section{AGRADECIMENTOS}

A equipe técnica do IAPAR responsável pelo monitoramento agorclimático do Paraná, através do Dr. Paulo Henrique Caramori, agroclimatologista por ceder a base de dados meteorológicos das estações da Rede do IAPAR.

Agradecemos também aos companheiros M.Sc. Aziz Benhamrouche, engenheiro agrônomo e membro do Grupo de Climatologia da UB, pelo apoio no uso do programa SURFER.8 e também ao professor Dr. Jonas Teixeira Nery, professor livre docente do Curso de Geografia da UNESP/Ourinhos-SP, pelo apoio na revisão do texto.

\section{REFERÊNCIAS BIBLIOGRÁFICAS}

AB'SÁBER, A. N. Os Domínios De Natureza No Brasil: Potencialidades Paisagistas. $1^{\text {a }}$ Edição, Ateliê Editorial. São Paulo. 2003.

BRASIL, Agencia Nacional de Transportes Aquaviário - ANTAQ. Anuário Estatístico Aquaviário. Movimentação Total de Cargas nos Portos Organizados por Natureza 2010. <http://www.antaq.gov.br/Portal/AnuarioEstatisticoAquaviario/InformacaoResul tado/Master.asp?ddlTabela $=18 \& d d I A n o=2010 \& d d I$ Capitulo=2\&ddISubCapitulo= 176>. Acesso em: 01. Abr. 2012.

CATALDI, M. e TORRES, A. R. South Atlantic SST anomalies impacts on the South Brazilian region climate through a numeric experiment with the model CAM 2.02 and data mining techniques, Proceedings of 8 ICSHMO, Foz do Iguaçu, Brazil, April 24-28, INPE, p. 521-531, 2006.

GASPAROTTO, F. K.; CARAMORI, P. H.; VASCONCELLOS, M. E. C. Análise de Tendência de Variáveis Climáticas e Hídricas para o Estado do Paraná. Publicações: Mudanças Climáticas e Agricultura no Paraná. Disponível em: <http://www.iapar.br/modules/conteudo/conteudo.php?conteudo=1390> Acesso em: 29 mar. 2012.

IBGE - Instituto Brasileiro de Geografia e Estatísticas. Censo Demográfico, 2010. Estados@. Disponível em: <http://www.ibge.gov.br/estadosat/perfil.php ?sigla=pr> Acesso em 29 mar. 2012.

IAPAR - Instituto Agronômico do Paraná. Agrometeorologia. Redes de Estações Meteorológicas do Paraná. Estações Meteorológicas Convencionais. Disponível em: <http://www.iapar.br/modules/conteudo/ conteudo.php?conteudo=890> Acesso em 29 mar. 2012.

INPE - Instituto Nacional de Pesquisas Espaciais. Centro de Previsões do Tempo e Estudos Climáticos. EI Niño e La Niña. Disponível em: <http://enos.cptec. inpe.br/> Acesso em: $30 \mathrm{dez} 2012$.

IPARDES - Instituto Paranaense de Desenvolvimento Econômico e Social. Perfil do Estado do Paraná. Disponível em: <http://www.ipardes.gov.br/perfil_ municipal/MontaPerfil.php> Acesso em 08 set. 2012. 
IPCC - Grupo Intergubernamental de Expertos sobre el Cambio Climático (IPCC). 2002. Cambio Climático y Biodiversidad. Documento Técnico V del IPCC. Disponível em: <http://www.ipcc.ch/pdf/technical-papers/climatechanges-biodiversity-sp.pdf> Acesso em: 14 set. 2012.

KANE, R.P. Limited effectivenes of EI Niños in causing doughts in ne Brazil and the prominet role of Atlantic parameters, Revista Brasileira de Geofísica, vol.19 no.2, São Paulo May/Aug. 2001.

KUCHARSKI, F.; POLZIN, D. e HASTENRATH, S. Teleconnection mechanisms of Northeast Brazil droughts: modeling and empirical evidence, Revista Brasileira de Meteorologia, v.23, n.2, 115-125, 2008.

LUCERO, O. A. Influencia de EI Niño-Oscilación del Sur en las lluvias sobre las cuencas de los ríos Paraná superior e Iguazú, Córdoba, CIHRSA, 1993.

MENDONÇA, F. de A. Geografia e meio ambiente. 4 ed. São Paulo: Contexto, 2001.

MIRANDA, E. E. de; (Coord.). Brasil em Relevo. Campinas: Embrapa Monitoramento por Satélite, 2005. Disponível em: <http://www.relevobr.cnpm. embrapa.br>. Acesso em: 18 maio 2012.

NOBRE, P.; SHUKLA, J. Variations of sea surface temperature, wind stress, and rainfall over the tropical Atlantic and South America. Journal of Climate, v.9, p.2464-2479, 1996.

TREWARTHA, G.T. \& L.H. HORN. An Introduction to Climate. McGraw-Hill, $5^{\text {th }}$ ed. New York. 1980. 